\title{
CONTRIBUIÇÕES DA GESTORA NA ORGANIZAÇÃO DA PRÁTICA PEDAGÓGICA NA VISÃO DAS PROFESSORAS
}

\author{
THE MANAGER'S CONTRIBUTIONS TO THE ORGANIZATION OF \\ PEDAGOGICAL PRACTICE IN THE VIEW OF TEACHERS
}

\author{
Carlos Alexandre Padilha da Silva ${ }^{1}$
}

Antonio Serafim Pereira ${ }^{2}$

\begin{abstract}
RESUMO: O presente estudo teve por objetivo compreender as contribuições da gestora na organização da prática pedagógica de uma escola pública na visão das professoras, assim como identificar no gestor aspectos referentes à organização pedagógica, analisando a contribuição da gestora na organização da prática pedagógica expressa no Projeto Político Pedagógico da escola pesquisada. Para isso, foi necessário estudar o papel da gestora frente à organização das práticas pedagógicas das professoras. Foi evidenciado como se desenvolve o trabalho na escola a partir da relação entre gestora e as docentes no que tange o trabalho pedagógico. A pesquisa de campo foi realizada por meio de entrevistas remotas, através do Google Meet, com três professoras pertencentes ao município de Criciúma. Através do diálogo com as professoras e com a análise de dados foi reconhecida a importância do gestor no desenvolvimento do trabalho pedagógico aliado a uma gestão democrática de cunho mais liberal.
\end{abstract}

PALAVRAS CHAVE: Contribuições; gestora; prática pedagógica; professoras.

\begin{abstract}
This study aimed to understand the contributions of the manager in the organization of the pedagogical practice of a public school in the view of the teachers, as well as to identify aspects related to the pedagogical organization in the manager, analyzing the manager's contribution in the organization of the pedagogical practice expressed in the Political Project Pedagogical of the researched school. For this, it was necessary to study the role of the manager in the organization of the teachers' pedagogical practices. It was shown how work is developed in the school from the relationship between the manager and the teachers regarding the pedagogical work. The field research was carried out through remote interviews, through Google Meet, with three teachers belonging to the municipality of Criciúma. Through dialogue with teachers and data analysis, the importance of the manager in the development of pedagogical work combined with a more liberal democratic management was recognized.
\end{abstract}

\footnotetext{
${ }^{1}$ Graduado em Pedagogia pela UNESC. pedagogia@unesc.net

${ }^{2}$ Doutor em Educação, Pós-doutorado em Ciências Humanas e Sociais; docente da UNESC/ Criciúma/ SC, Email: asp@unesc.net
}

Saberes Pedagógicos, Criciúma, v. 5, n² 2, maio/agosto 2021.- Curso de Pedagogia- UNESC 
KEYWORDS: Contributions; manager; pedagogical practice; teachers.

\section{INTRODUÇÃO}

Este trabalho surgiu a partir da minha atuação no Programa Institucional de Bolsas de Iniciação à Docência (PIBID) do Governo Federal. Participei do Programa de agosto de 2018 a setembro de 2019 em uma escola pública de Criciúma - SC, atuando nos anos iniciais do Ensino Fundamental. Até o momento, não havia passado pelas disciplinas de estágio obrigatório e não tinha nenhuma experiência em sala de aula. Nesse período, percebi que a gestora escolar da instituição acompanhava atentamente o trabalho dos professores em sala de aula, não se atendo somente às atividades burocráticas do cargo.

A gestora demonstrou interesse em me auxiliar no processo de construção profissional, analisando meus projetos e sugerindo conteúdos. Partindo dessa análise informal, resolvi problematizar a questão pelo ângulo dos professores, a fim de investigar se as orientações pedagógicas que recebi se estendiam a eles. Com base nesta inquietação, o problema de pesquisa ficou assim delimitado: de que forma o gestor escolar contribui na organização da prática pedagógica na visão das professoras?

O presente trabalho tem como objetivo central compreender as contribuições do gestor nesta organização pedagógica. Especificamente, a pesquisa busca: a) identificar aspectos da organização da prática pedagógica, relativos às ações da gestora, na visão dos professores; b) analisar a contribuição do gestor na organização da prática pedagógica expressa no Projeto Político Pedagógico da escola pesquisada.

A pesquisa se destina a acadêmicos, professores e comunidade em geral. Ainda, pode contribuir através da reflexão sobre o papel do gestor - que é o representante do meio (gestão) que deve oferecer para a atividade fim (aprendizagem dos alunos). Esta pesquisa também poderá contribuir para qualificar o processo de aprendizagem dos alunos, bem como, a revisão das práticas pedagógicas existentes na escola, observando o papel do gestor como articulador das aprendizagens, destacando a influência do gestor para transformar o a realidade atual da educação no país. 


\section{SABERES PEDAGÓGICOS}

Revista do Curso de Graduaçào de Pedagogia - Unesc

ISSN 2526-4559
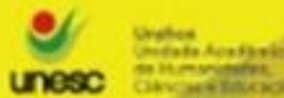

\section{CONTRIBUIÇÃO DA GESTÃO ESCOLAR NO PENSAMENTO/ORGANIZAÇÃo DO ENSINO}

Um gestor deve estar aberto ao diálogo, discussões e estudos sem deixar de lado suas responsabilidades burocráticas, se atentando na condução e coordenação do que está propondo. De acordo com Lück (2000), é o diretor que mobiliza os atores educacionais no processo de construção de um ambiente educacional que garanta a formação de estudantes.

Nesse sentido, as atividades do gestor são ampliadas e ele deve manter a organização e o funcionamento da instituição em todos os aspectos, inclusive no âmbito pedagógico, visando garantir a qualidade de ensino oferecido. Portanto, acreditamos ser de extrema importância para os profissionais de educação sentirem que são acolhidos e amparados em sua unidade escolar. Esse apoio pode ser uma importante ferramenta para a melhoria da educação, o quê de fato acaba beneficiando toda a sociedade.

A educação constitui-se direito fundamental e essencial dos seres humanos e diversos são os textos normativos e leis que apresentam tal informação. A Constituição Federal de 1988 apresenta a educação como direito de todos e dever da família.

Muito do trabalho educativo para a busca da emancipação dos sujeitos, como prevê a Constituição, passa pelo trabalho da gestão escolar, que é o principal responsável pela instituição. Dessa maneira, a função social da escola é formar cidadãos com valores, visões, opiniões e que saibam viver em sociedade harmonicamente, respeitando a diversidade, assim como a natureza na qual vivem, contribuindo para o desenvolvimento coletivo.

Inicialmente, ao pensar em gestão escolar, essa ideia remete a gerir/administrar/conduzir uma unidade escolar ou instituição com eficiência. O líder gestor, nesse sentido, seria o articulador entre todas as práticas presentes na instituição, significativas ou não, democráticas ou não. Ele deve buscar a mobilização do grupo.

Um dos papéis da escola na construção da aprendizagem escolar, segundo Aquino (2002, p. 71):

É de estimular a curiosidade e o inquietamento de ideias do aluno por meio da reflexão e da provocação feita pelo educador. Assim, observa que para ele a escola é

Saberes Pedagógicos, Criciúma, v. 5, n², maio/agosto 2021.- Curso de Pedagogia- UNESC 
um lugar onde acolhemos as diversidades e construímos novos conceitos ao redor do que já conhecemos (AQUINO, 2002, p. 71).

No exercício das suas atribuições, espera-se que um gestor esteja em constante formação, ou seja, que esteja sempre buscando conhecimentos e aprimoramentos, criando dessa forma bagagens de experiências enriquecidas, para que isso o auxilie nas tomadas de decisões e possibilite um compartilhamento destes novos conhecimentos com seus pares, favorecendo o desenvolvimento profissional do coletivo.

O gestor enquanto líder precisa estar pronto para atender as demandas, realizar as mudanças exigidas, cabendo a ele motivar, apoiar e monitorar a equipe de trabalho, elevando a expectativa dos docentes em relação à aprendizagem. Com base nessa perspectiva, o papel pedagógico do gestor é fundamental, pois ele pode auxiliar na prática pedagógica do professor, oferecendo ferramentas e possibilitando que a instituição consiga alcançar os objetivos propostos. Todos os atores envolvidos neste processo devem priorizar os mesmos objetivos a fim de garantir as aprendizagens.

Nesse processo, o gestor que exerce sua liderança, assume a função de facilitador, realiza a mediação das práticas de ensino utilizadas pelos professores, propõe meios didáticos e materiais para que possam desenvolver boas metodologias em suas práticas pedagógicas. Estes são os componentes que fazem uma escola democrática onde gradativamente se consegue atingir os objetivos dos quais os membros se tornam agentes de transformação da sociedade.

Conforme Lacerda (2011), ter foco no pedagógico, saber trabalhar em equipe, comunicar-se com eficiência, identificar a necessidade de transformações e estimular a promoção da aprendizagem dos profissionais que trabalham com ele são algumas das competências que um gestor deve ter.

Na medida em que o gestor educacional domina os aspectos relacionados à gestão, também precisa se adequar a mudanças, pois os avanços são rápidos. Requer-se dos educadores uma nova postura diante do processo de ensino-aprendizagem e da educação em geral, que compreendam as mudanças que vão ocorrendo ao longo da história e se adaptem a elas.

Saberes Pedagógicos, Criciúma, v. 5, n², maio/agosto 2021.- Curso de Pedagogia- UNESC 
Nas escolas, onde há integração entre os professores, os resultados pedagógicos são propensos a serem mais significativos. Segundo Lück (2004), a maior responsabilidade da instituição escolar é do diretor, em relação ao desenvolvimento da política educacional adotada, assim como o desenvolvimento e organização de esforços para alcançar os objetivos educacionais.

Devido a sua posição central na escola, o desempenho do gestor exerce forte influência (tanto positiva, como negativa sobre todos os setores pessoais da escola). Muitas vezes, isso é identificado em falas que afirmam que a escola é a "cara" do gestor.

Ao mesmo tempo, a equipe escolar possui funções determinadas, mas no mundo educacional é necessário mais do que cumprir as suas atividades e tarefas rotineiras, pois todos são educadores e devem promover através do relacionamento e da atuação uma educação emancipatória e de qualidade. Falar em qualidade é avaliar a educação que se oferece na instituição escolar, pois a qualidade se constrói num processo de pequenas ações, sendo cada uma delas importante por si mesma e pelo conjunto que formam. Dessa maneira, buscar a qualidade é democratizar a educação e torná-la assim mais justa, acessível e igualitária.

Constata-se, desse modo, que muitas dificuldades são encontradas para exercer as funções, tais como escassez de recursos financeiros, falta de pessoal qualificado, deficiência na estrutura física e material, falta de autonomia frente às normas impostas pelo Governo, além do excesso de trabalho burocrático que diminui o tempo para uma maior dedicação no processo pedagógico. No entanto, pode-se afirmar que mesmo com muitos empecilhos, os gestores que mantém parcerias com os demais segmentos, conseguem administrar com mais eficiência e eficácia o processo de ensino-aprendizagem. A inovação no campo educacional e a sua efetivação na prática incidem sobre as pessoas envolvidas no processo, ou seja, serão os professores, coordenadores, gestores e toda a equipe de funcionários da escola os responsáveis pelas mudanças que ocorrerão. 


\section{1 PERSPECTIVAS DE GESTÃO ESCOLAR}

O trabalho de gerir uma escola é composto por vários aspectos e exige um olhar centrado do gestor em várias direções. Nesse sentido, são conhecidas diferentes concepções de gestão do sistema educacional brasileiro. Libâneo, Oliveira e Toschi (2017, p. 238) consideram que:

\footnotetext{
As concepções de educação escolar referem-se a determinados modos de compreender as modalidades de educação, as funções sociais e pedagógicas da escola, os objetivos educativos, as dimensões da educação, os objetivos de aprendizagem, o currículo, os conteúdos e a metodologia de ensino, as formas de organização e gestão.
}

A partir dos anos 1980, com discussões sobre a reforma curricular dos cursos de Pedagogia e de Licenciaturas, passou-se a pensar nas concepções de organização e gestão da escola. Dentro da perspectiva técnico-científica, o gestor acredita que a escola deve instruir, programar e operacionalizar o ensino e fica evidente a relação de poder e a subordinação, uma vez que o poder é centralizado no diretor. A comunicação sempre se dá de cima para baixo e é baseada em normas e regras, sempre dando maior ênfase nas tarefas do que nas pessoas.

Na perspectiva democrática liberal, o gestor pede sugestões, consulta a equipe, mas tudo já está decidido antes, a democracia é um "disfarce", como destaca Pereira e Mueller (2019, p. 243):

\footnotetext{
Mediante o discurso da contextualização, considera a escola o centro da gestão e proclama a autonomia escolar, que deve se desenvolver a partir da participação de pais, professores, alunos e comunidade na reestruturação da educação, visando ao uso racional dos recursos para garantir maior eficiência e qualidade dos serviços oferecidos. A lógica que a sustenta é bastante evidente: a do mercado (PEREIRA \& MUELLER, 2019, p. 243).
}

Assim como Libâneo, Oliveira e Toschi (2017) destacam a perspectiva democrático participativa, a pedagogia tradicional fortalece a perspectiva técnico científica. Já Pereira e Mueller (2019), por sua vez, apresentam as perspectivas centralizada e democrática desdobrada em liberal e participativa. 
A perspectiva democrática liberal é constituída dentro de um movimento de participação com baixa intensidade. Nesta, a democracia é um procedimento que deve cumprir as regras impostas como democráticas, sem possibilidade de participação direta (PEREIRA; MUELLER, 2019, p. 244).

Diferente das outras duas perspectivas, a gestão democrática participativa se apresenta como um contraponto em relação às outras concepções. De acordo com Pereira e Mueller (2019, p.242), “A gestão democrática participativa, por sua vez, tem na participação direta a estratégia básica de discussão e tomada de decisão das questões de interesse coletivo, especialmente no que diz respeito à educação escolar enquanto direito público e social". Desse modo, se busca desenvolver a autonomia da escola e da comunidade escolar, o gestor permite que os professores atuem com liberdade e autonomia e, essa proposta busca a participação da comunidade escolar, no qual todos dirigem e são dirigidos.

De acordo com a Base Nacional Comum Curricular, diretores, professores e coordenadores devem ter a aprendizagem como sentido para todas as suas atividades, atuando no ambiente escolar de forma a contribuir para a construção de um ambiente escolar em que se manifestem as competências gerais nos estudantes.

Da mesma forma, o currículo faz parte desse processo de construção do conhecimento e sabe-se que o currículo possui uma intencionalidade. É necessário que o conhecimento deixe de ser uma informação e passe a ser uma proposição. Para isso, é preciso ter uma intenção pedagógica.

Para o desenvolvimento das competências gerais nos alunos, é necessária uma prática pedagógica que pode ser tradicional ou crítica. A prática educativa é uma realidade complexa que passa por um currículo:

[...] o currículo faz parte, na realidade, de múltiplos tipos de práticas que não podem reduzir-se unicamente à prática pedagógica de ensino; ações que são de ordem política, administrativa, de supervisão, de produção de meios, de criação intelectual, de avaliação, etc., e que, enquanto são subsistemas em parte autônomos e interdependentes, geram forças que incidem na ação pedagógica (SACRISTÁN, 1998, p. 22).

Na prática pedagógica tradicional, o professor é o agente principal da "transmissão" do conhecimento e os alunos recebem esse conteúdo. Seu método é marcado por um ensino Saberes Pedagógicos, Criciúma, v. 5, n², maio/agosto 2021.- Curso de Pedagogia- UNESC 
que se volta para o que a sociedade impõe através da legislação, desconsiderando, dessa forma, a experiência e a realidade vivenciada pelos alunos. A memorização forma o processo educativo e as avaliações são utilizadas para medir a qualidade do que se é aprendido na unidade escolar.

Na prática pedagógica crítica, como expõe Contreras (2002), à reflexão crítica vislumbra um processo de tomada de consciência do educador que vai além de suas próprias intenções, pois a criticidade que permeia esta reflexão, permite-lhe questionar a estrutura social que acaba por envolver seu trabalho, possibilitando-o, uma noção crítica e consciente da prática por ele desenvolvida e dos impactos dessa prática social na sua atividade docente.

\section{METODOLOGIA, APRESENTAÇÃO E ANÁLISE DE DADOS}

A pesquisa realizada, considerando seus objetivos, configura-se como de natureza básica qualitativa, exploratória, desenvolvida em uma escola pública municipal de Ensino Fundamental da cidade de Criciúma - SC. Segundo Severino, (2007, p.123) "busca apenas levantar informações sobre determinado objeto, delimitando assim um campo de trabalho, mapeando as condições de manifestação desse objeto". A escolha da instituição deu-se a partir da minha experiência no PIBID, atuando na unidade escolar, sempre em contato com a gestora. Quanto aos objetivos da pesquisa, ela se classifica como exploratória. A pesquisa visou compreender como descrito anteriormente, as contribuições do gestor na organização pedagógica na visão dos professores.

A pesquisa foi desenvolvida com três professoras do ensino fundamental, de maneira remota, em vista da pandemia, com foco de compreender as contribuições da gestora na organização da prática pedagógica das professoras. Fizeram parte dela três professoras do $3^{\circ}$, $4^{\circ}$ e $5^{\circ}$ ano do referido nível de ensino. As entrevistadas possuem formação em Pedagogia e são pós-graduadas. Serão identificadas de P1, P2 e P3. Por questões éticas, não serão reveladas as identidades das professoras entrevistadas, foram utilizados pseudônimos para elas.

O instrumento principal utilizado para a entrevista foi a entrevista semiestruturada, mediante adesão voluntária e autorização das participantes. Os tópicos básicos da entrevista

Saberes Pedagógicos, Criciúma, v. 5, n², maio/agosto 2021.- Curso de Pedagogia- UNESC 
foram: relação professor/docente; acompanhamento do gestor em relação à prática pedagógica dos professores; auxílio da gestora na prática pedagógica dos professores e; trabalho da gestora em relação ao Projeto Político Pedagógico da instituição. A coleta de dados ocorreu da seguinte forma: $1^{\mathrm{o}}$ Momento: Convite para a profissional participar da pesquisa. $2^{\circ}$ Momento: Entrevistas realizadas em datas e horários diferentes, conforme a disponibilidade de tempo do acadêmico e das professoras participantes. No encontro foi aplicada uma entrevista via Google Meet. $3^{\circ}$ Momento: Transcrição das entrevistadas conforme gravação via Google Meet.

Após o cumprimento de todas essas etapas, foi realizada a interpretação e análise crítica dos dados obtidos, a partir das seguintes categorias: relação gestor/docente; acompanhamento da gestora em relação à prática pedagógica das professoras; auxílio da gestora na organização da prática pedagógica; trabalho da gestora referente ao Projeto Político Pedagógico com as professoras.

\subsection{ANÁLISE}

É através da análise crítica dos dados obtidos nas entrevistas que visamos contemplar os objetivos da presente pesquisa. A partir das falas das professoras entrevistadas, quanto à relação gestora/docente, concluímos que uma professora diverge das outras duas entrevistadas. A entrevistada P1, falou sobre a gestora ouvir pais e professores. O fato de ouvir pode estar relacionado a uma boa relação ou a uma gestão democrática.

Para representar esse entendimento, P1 disse isso: "Ela sempre ouve professores, ouve pais, alunos, é uma pessoa fantástica." Para representar sua posição, P2 disse que a gestora oferece apoio, em uma espécie de tutela, além de se relacionar bem e apoiar, como se observa em sua fala: "Ela é muito simpática, acessível, trata a gente de igual pra igual, passa segurança, é ética, oferece apoio sempre que a gente precisa, em todos os sentidos."

Já a entrevistada P3, assim como a entrevistada P2, afirma que a gestora está disposta a apoiar, dar assistência, isso dentro de um procedimento de auxílio e de ajuda. P3 diz: "Ela é maravilhosa, como gestora, como pessoa, ela deixa o administrativo e vem ajudar a gente. É muito parceira."

Saberes Pedagógicos, Criciúma, v. 5, n², maio/agosto 2021.- Curso de Pedagogia- UNESC 
Nesse sentido, P1 responde diferente das outras, não aparece em sua fala que a gestora é acessível, as três a consideram simpática, mas apenas duas falam que é acessível (P2 e P3). As três entrevistadas disseram que a gestora é excelente profissional, uma diz que é ética outra diz que ela ouve. Pode-se entender que ouvir, nesse sentido, pode ser uma possibilidade democrática. Se esse ouvir estiver no sentido de tomar decisões, discutir questões referentes à escola e ao currículo de forma a contemplar a posição de pais e alunos, se trata de uma gestão democrática participativa. Como destaca Libâneo (2001, p. 100), pode se dizer "[...] concebem a participação de todos nas decisões como importantes ingredientes para a criação e desenvolvimento de relações democráticas e solidárias."

Referente ao acompanhamento da gestora em relação à prática pedagógica das professoras, as três entrevistadas relataram a presença da gestora em relação à prática delas. Entende-se como presença física, em forma de assistência, cobertura e apoio. Isso se evidencia na fala da P1: "Ela está sempre nos ouvindo, vai à sala de aula, olha cadernos, olha o nosso planejamento, conversa com pais, ajuda a tirar dúvidas, sempre está à disposição". Novamente, verifica-se o apoio da gestora, dito pelas professoras entrevistadas. Porém, o fato de ouvir os pais pode se desdobrar em dois sentidos, um relativo à sala de aula, aos processos de ensino e aprendizagem e a própria execução do trabalho, ou em relação ao bom relacionamento com os pais para manter uma boa convivência.

Indo nesse sentido, a entrevistada P2 destaca o apoio que a gestora dá no desenvolvimento do seu trabalho em sala de aula: "Quando a gente se vê em alguma situação nova em sala de aula, ela nos auxilia". Da mesma forma, P3 trás em sua fala também o apoio e a presença da gestora no desenvolvimento do seu trabalho como professora. P3 afirma: "Ela orienta, acompanha, todos os dias no primeiro horário ela vai às salas, fala com os professores, conversa com os alunos. Isso acaba auxiliando bastante."

Não foi possível entender qual é o objetivo de conhecer todos os alunos e todos os pais, através das falas das entrevistas, pode se tratar de uma conversa dialógica, mas acreditamos se tratar de uma perspectiva democrática liberal. A perspectiva democrática liberal é constituída dentro de um movimento de participação com baixa intensidade. Nela, a democracia é um procedimento que deve cumprir as regras impostas como democráticas, sem possibilidade de participação direta (PEREIRA; MUELLER, 2019).

Saberes Pedagógicos, Criciúma, v. 5, n², maio/agosto 2021.- Curso de Pedagogia- UNESC 


\section{SABERES PEDAGÓGICOS}

Revista do Curso de Graduaçào de Pedagogia - Unesc

ISSN 2526-4559

No que tange ao auxílio da gestora na organização da prática pedagógica na visão das professoras, P1 fala sobre sua experiência profissional, mais uma vez se evidencia o apoio, a assistência e a participação da gestora, na qual afirma a entrevistada P1: "eu já conheço bem o trabalho, mas ela percebe quando a gente está com dúvidas. Ela ajuda, dá dicas, esse ano ela pediu que a gente fosse mais light com eles, pois não tiveram aulas presenciais ano passado." Não consta, nas falas das entrevistas, nada referente a discussão do currículo escolar e sim a execução do trabalho das professoras. Ou seja, existe uma preocupação com o fazer e com a forma. Mediante o discurso da contextualização da escola, ela é considerada o centro da gestão, em que a participação da comunidade escolar na reestruturação da educação visa garantir maior qualidade dos serviços escolares. Isso tudo se sustenta em uma lógica de mercado. (PEREIRA; MUELLER, 2019).

A professora entrevistada $\mathrm{P} 2$, fala em autonomia, proporcionada pela gestora, que mais uma vez se mostra estar à disposição da professora. P2 destaca: "Ela pede que a gente use atividades complementares quando sobra tempo, vê provas, ela faz parte de coordenadora pedagógica, pois a escola não tem uma”.

Falando em produção de conhecimento, a entrevistada P3 destaca: "Ela acompanha para ver se o conhecimento está chegando em cada um. Como conhece todos os alunos e familiares, consegue identificar quando o aluno está com algum problema fora da escola e auxilia nesse sentido.” Infere-se, a partir das falas, que se trata de uma gestão democrática liberal, em que as decisões são tomadas coletivamente através de discussões públicas. Nesse sentido, a democracia não está decidida nem construída, ela é o resultado de um processo de construção da liberdade através da convivência humana (PEREIRA; MUELLER, 2019).

Quanto ao trabalho do gestor referente ao Projeto Político Pedagógico, duas delas disseram que não tiveram acesso ao documento no ano de 2021, e uma delas enfatizou o trabalho desenvolvido através do Projeto Político Pedagógico. Evidencia P1: "Na reunião foi falado sobre o PPP, como funcionaria, como são as regras, mas a parada pedagógica esse ano ainda não tivemos. O PPP está sendo modificado, então acredito que depois iremos trabalhar na nova versão.”

A entrevistada P2 frisa: "Foi feito um trabalho no ano passado, nesse ano o PPP está sendo reformulado. Como o ano passado foi praticamente todo online, vai ter modificações

Saberes Pedagógicos, Criciúma, v. 5, n², maio/agosto 2021.- Curso de Pedagogia- UNESC 
sobre isso, sobre atividades online e sobre como os alunos aprendem."

O trabalho desenvolvido através do Projeto Político Pedagógico é destacado pela entrevistada P3: "Sim, todo início do ano é feito um trabalho com ele, esse ano não teve em função da pandemia. Ela quer que todos os professores conheçam e apliquem o que está no PPP. Por isso a escola é maravilhosa". Verifica-se preocupação da gestora com a aprendizagem dos alunos e com a execução de um bom trabalho. A fala delas não dá indicativo de que houve participação das entrevistadas na reformulação do Projeto Político Pedagógico.

No Projeto Político Pedagógico da instituição, referente à dimensão administrativa em relação ao gestor e a coordenação pedagógica, encontramos que "a função da coordenação pedagógica nas escolas deve ser de acompanhamento, problematização do cotidiano escolar e assessoria aos profissionais para o desenvolvimento da práxis pedagógica, tanto individual quanto coletiva" (2018, p. 39).

Esses elementos presentes no Projeto Político Pedagógico foram encontrados nas entrevistas, principalmente nas questões de acompanhamento e assessoria aos profissionais da educação. O Projeto Político Pedagógico é um instrumento de gestão democrática, previsto em lei.

\section{CONCLUSÃO}

Neste estudo, foram traçadas reflexões no sentido de compreender as contribuições da gestora em relação ao trabalho pedagógico das professoras. Fica evidente a importância de ouvir alunos, pais e professores, no sentido da existência da democracia em seu sentido mais amplo. Desse modo, quando o gestor consegue trabalhar o administrativo aliado às funções pedagógicas, os resultados podem ser benéficos para toda a comunidade escolar, principalmente aos alunos.

$\mathrm{Na}$ participação da gestora como forma de apoiar as professoras, no entanto, não verificamos discussão em relação ao currículo escolar e na reformulação do Projeto Político Pedagógico. Existe uma evidente preocupação com o atender bem os alunos e com o fazer 
docente, porém, não se verificou traços de gestão democrática participativa por não envolver reflexão e decisão coletiva sobre questões que envolvem a proposta pedagógica da escola.

O acompanhamento do trabalho dos professores, assim como o acompanhamento no sentido de verificar se o conhecimento transmitido está sendo apropriado pelos alunos, pode ser uma possibilidade de emancipação destes. Basta saber, no entanto, de que forma. Para fazermos uma afirmação mais objetiva considerando que os dados das entrevistas não nos favorecem nesse sentido.

Desse modo, defendemos que novos e constantes estudos possibilitem, aos gestores, a ampliação do caminho trilhado com alternativas que despertem o compromisso de realizar experiências mais democráticas voltadas à formação plena de crianças e jovens, de forma que valorize o conhecimento e a realização pessoal e coletiva de todos, oferecendo assistência aos membros da escola para que promovam ações condizentes com os princípios e objetivos educacionais intencionados.

\section{REFERÊNCIAS}

AQUINO, J. G. Diálogo com educadores: o cotidiano escolar interrogado. São Paulo: Moderna, 2002.

BRASIL. Ministério da Educação. Base Nacional Comum Curricular. Brasília, 2018. Disponível em: < http://basenacionalcomum.mec.gov.br/> . Acesso em: 20 abr. 2021.

CONTRERAS, José. Autonomia dos professores. São Paulo: Cortez, 2002

LACERDA, Eliane. Padrões de competência do diretor. Belo Horizonte. 2011

LIBÂNEO, José Carlos. Organização e Gestão da escola: teoria e prática. Revista e Goiânia: Alternativa, 2001.

LIBÂNEO, José Carlos; OLIVEIRA, João Ferreira; TOSCHI, Mirza Seabra. Educação escolar: políticas, estrutura e organização. São Paulo: Cortez, 2017.

LÜCK, Heloísa: A escola participativa: o trabalho do gestor escolar. Rio de janeiro: DP\&A editora. Coleção Magistério: Formação e trabalho pedagógico. 2000.

LÜCK, Heloísa: Ação integrada: administração supervisão e orientação educacional. 22 Ed. Petrópolis, 2004

Saberes Pedagógicos, Criciúma, v. 5, n² 2, maio/agosto 2021.- Curso de Pedagogia- UNESC 
NEVES, José Luis. Pesquisa qualitativa: características, usos e possibilidades. Caderno de Pesquisas em Administração, São Paulo, v. 1, n. 3, p.01 -05, 1996.

PEREIRA, Antonio; MUELLER, Rodrigo. PEREIRA, Gestão democrática e sistemas municipais de educação: ampliando o olhar. In: PEREIRA, Antonio Serafim; REGO, Miguel Anxo Santos. Educação: partilhando e ampliando audiências, resistências e repertórios. Criciúma, SC. Unesc, 2019.

CRICIÚMA. Projeto político pedagógico da rede de educação de criciúma. Secretaria Municipal de educação. 2018.

SACRISTÁN, José Gimeno. O currículo: uma reflexão sobre a prática. Porto Alegre: Artmed, 2000.

SEVERINO, Antonio Joaquim. Metodologia do trabalho científico. 23. Ed. São Paulo: Cortez, 2007 